\title{
X-ray photoelectron spectroscopic study on sapphire nitridation for GaN growth by hydride vapor phase epitaxy: Nitridation mechanism
}

\author{
F. Dwikusuma and T. F. Kuech ${ }^{\mathrm{a})}$ \\ Department of Chemical and Biological Engineering, University of Wisconsin-Madison, \\ Madison, Wisconsin 53706
}

(Received 1 April 2003; accepted 12 August 2003)

\begin{abstract}
The nitridation of $c$-plane sapphire within the hydride vapor phase epitaxy system was systematically studied as a function of time and ammonia partial pressure using ex situ x-ray photoelectron spectroscopy, reflection high-energy electron diffraction, and atomic force microscopy. During the nitridation process, nitrogen was incorporated into the sapphire surface. There were two different nitrogen chemical bonding states, which can be attributed to $\mathrm{N}-\mathrm{Al}$ bonds and nitrogen in oxygen-rich environment (' $\mathrm{N}-\mathrm{O}$ '). As the nitridation continued, the $\mathrm{N} 1 s$ intensity increased while the $\mathrm{O} 1 s$ intensity decreased indicating the growth of a nitrogen-rich layer. The sapphire nitridation process can be modeled as a diffusion couple of $\mathrm{AlN}$ and $\mathrm{Al}_{2} \mathrm{O}_{3}$, where $\mathrm{N}^{3-}$ and $\mathrm{O}^{2-}$ interdiffuse in the rigid $\mathrm{Al}^{3+}$ framework. Nitrogen diffuses into sapphire and substitutes for oxygen to bond with aluminum. The bond substitution is accompanied by structural changes where the AlN in-plane direction is rotated $30^{\circ}$ with respect to the sapphire direction. The replaced oxygen diffuses out to the surface, combines with hydrogen and desorbs as $\mathrm{H}_{2} \mathrm{O}$. The overall nitridation rate is determined by the slower of the two moving anions. From the $\mathrm{x}$-ray photoelectron spectroscopy data, the chemical diffusion coefficient of nitrogen $\left(\widetilde{D}_{\mathrm{N}}\right)$ and oxygen $\left(\widetilde{D}_{\mathrm{O}}\right)$, were estimated. $\widetilde{D}_{\mathrm{N}}$ was found to be higher than $\widetilde{D}_{\mathrm{O}}$, which suggested that the overall nitridation rate was controlled by the diffusion of oxygen to the surface. After nitridation, no protrusions were observed on the surface and no significant changes in the surface roughness were measured when compared to the as-received sapphire. (C) 2003 American Institute of Physics. [DOI: 10.1063/1.1618357]
\end{abstract}

\section{INTRODUCTION}

Sapphire $\left(\alpha-\mathrm{Al}_{2} \mathrm{O}_{3}\right)$ has been widely used as a substrate for $\mathrm{GaN}$ growth despite having a $\sim 16 \%$ lattice mismatch and $\sim 34 \%$ thermal expansion coefficient mismatch with $\mathrm{GaN}$. The pregrowth treatment of the sapphire substrate can greatly affect GaN nucleation, which subsequently determines the structural and optical properties of the epitaxial film. It is now well established that the nitridation of sapphire surface prior to $\mathrm{GaN}$ growth can improve the material properties in metalorganic vapor phase epitaxy (MOVPE), ${ }^{1,2}$ molecular beam epitaxy (MBE), ${ }^{3,4}$ and hydride vapor phase epitaxy (HVPE) $)^{5,6}$ growth techniques.

There have been a number of studies on the nitridation of sapphire in the MOVPE ${ }^{2,7-12}$ and $\mathrm{MBE}^{3,4,13-22}$ environments using different nitrogen sources and carrier gases at various pressures and temperatures. The growth environment and growth process in HVPE are substantially different from those of MOVPE and MBE. HVPE growth is typically done at atmospheric pressure, while a typical system pressure for MOVPE and MBE growths is $\sim 76$ and $<10^{-3}$ Torr, respectively. HVPE primarily uses a $\mathrm{N}_{2}$ carrier gas, whereas MOVPE mainly uses a $\mathrm{H}_{2}$ carrier gas. The nitridation source in HVPE and MOVPE is $\mathrm{NH}_{3}$; while in MBE, nitridation can be carried out using $\mathrm{NH}_{3}$ or one of many plasma sources, including an electron cyclotron resonance (ECR) and a radio-frequency (rf) nitrogen plasma. There is a general con-

${ }^{a)}$ Electronic mail: Kuech@engr.wisc.edu sensus among all sapphire nitridation studies that nitrogen was incorporated into the sapphire surface layer. The surface compound containing nitrogen, formed upon nitridation, and the surface morphology after nitridation seems to largely depend on the nitrogen source used and the nitridation conditions (i.e., temperature, pressure, flow rates, and carrier gas). ${ }^{2-22}$ Therefore, the impact and mechanism of sapphire nitridation within the HVPE system can be expected to be different from the previous results obtained in the MOVPE and MBE environments.

Several nitridation studies in MOVPE have observed the formation of an amorphous aluminum oxynitride $\left(\mathrm{AlN}_{x} \mathrm{O}_{1-x}\right)$ layer, ${ }^{2,7}$ while other studies presented evidence for the formation of relaxed crystalline AlN on the sapphire surface. ${ }^{8,9}$ Studies on sapphire nitridation in a MBE system using a rf nitrogen plasma suggested the formation of AlN and NO molecules on the sapphire, ${ }^{3,23}$ as well as an $\mathrm{AlN}_{x} \mathrm{O}_{1-x}$ intermediate compound. ${ }^{4}$ In some cases, a crystalline AlN layer was reportedly formed during sapphire nitridation in MBE using $\mathrm{NH}_{3},{ }^{13,14}$ an ECR nitrogen plasma, ${ }^{15,16}$ and a helicon-wave nitrogen plasma. ${ }^{17}$ Using a constricted nitrogen plasma, it was demonstrated that both AlN and $\mathrm{AlN}_{x} \mathrm{O}_{1-x}$ compounds were formed during sapphire nitridation. ${ }^{18}$ The surface morphology of sapphire after nitridation was dependent on the nitrogen source and nitridation condition, i.e., the nitridation time and temperature. A high density of protrusions has been observed after long nitrida- 
tion ( $<20 \mathrm{~min}$ ) in $\mathrm{MOVPE}^{2,7,12}$ and MBE using both a rf nitrogen plasma ${ }^{19-22}$ and a constricted plasma $^{18}$ sources. With the rf nitrogen plasma source, the formation of protrusions also depends on nitridation temperature. In contrast, negligible change in the sapphire surface roughness was observed in nitridation studies in MBE, using a $\mathrm{NH}_{3}$ source ${ }^{14}$ and an ECR nitrogen plasma, for process times up to 180 min. ${ }^{15}$

The state of the pregrowth surface, after the nitridation of sapphire in the HVPE growth system, can be expected to be different from what has been observed in nitridation studies using other growth techniques. In addition, in spite of the work of many authors on the nitridation process, a detailed understanding of the nitridation mechanism is still needed. In this article, the nitridation of $c$-plane sapphire within the HVPE system was systematically studied as a function of time and $\mathrm{NH}_{3}$ partial pressure. Nitridation time and $\mathrm{NH}_{3}$ partial pressure are the two important variables in the HVPE system, since the temperature and total pressure are typically fixed to a constant value. The chemical state, structure, and morphology of sapphire surface after nitridation were characterized using ex situ x-ray photoelectron spectroscopy (XPS), reflection high-energy electron diffraction (RHEED), and atomic force microscopy (AFM). The results are discussed in terms of nitridation mechanism that is consistent with the experimental data.

\section{EXPERIMENT}

The $c$-plane sapphire was ultrasonically cleaned in acetone, methanol, and rinsed in deionized (DI) water. The nitridation of sapphire was performed in the backflow region of a vertical HVPE system under a $\mathrm{NH}_{3}$ and $\mathrm{N}_{2}$ ambient at $1100^{\circ} \mathrm{C} .^{5}$ The backflow region allows the sample to be heated to the growth temperature of $1100{ }^{\circ} \mathrm{C}$ under a countercurrent gas flow, protecting the sample from gallium precursor gas flow. Prior to nitridation, the sapphire was heated to $1100{ }^{\circ} \mathrm{C}$ under $\mathrm{N}_{2}$ atmosphere for $5 \mathrm{~min}$. Nitridation was carried out by exposing the sapphire to a mixture of $\mathrm{NH}_{3}$ and $\mathrm{N}_{2}$ at a total flow rate of $2 \mathrm{slpm}$ and a total pressure of $1 \mathrm{~atm}$. The nominal reactor diameter near the sapphire was $6 \mathrm{~cm}$. Three $\mathrm{NH}_{3}$ partial pressures $\left(P_{\mathrm{NH}_{3}}\right)$ were studied: $0.2,0.5$, and 1 atm. At each $P_{\mathrm{NH}_{3}}$ value, the nitridation time was varied from 5 to $60 \mathrm{~min}$. Several samples of each experimental condition were studied.

After nitridation, the chemical composition of sapphire surface was examined using an ex situ XPS. Since the XPS measurements were carried out ex situ, specific care was taken to determine the extent of reaction with the air ambient and to appropriately correct for any air-induced changes in the surface chemistry. The XPS measurements were performed using a photoelectron takeoff angle, $\theta$, of $45^{\circ}$ with a $\operatorname{Mg} K \alpha$ line $(1253.6 \mathrm{eV})$ as the $\mathrm{x}$-ray source. High resolution scans corresponding to an instrumental energy resolution of $\sim 0.5 \mathrm{eV}$ full width at half maximum (FWHM) were utilized for individual peak analysis. The core-level photoemission binding energies were corrected for sample charging using the adventitious surface carbon, $\mathrm{C} 1 \mathrm{~s}$, binding energy at $284.8 \mathrm{eV}$. The normalized concentration of $\mathrm{N} 1 \mathrm{~s}$ and $\mathrm{O} 1 \mathrm{~s}$

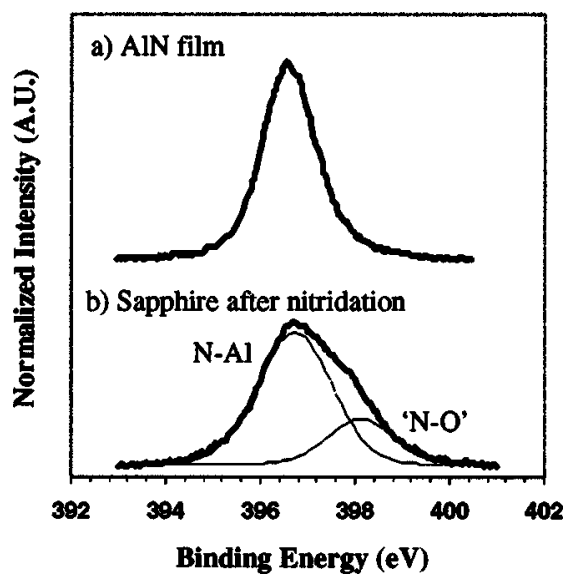

FIG. 1. High resolution XPS spectra of the N $1 s$ photoelectron peak from (a) a standard AlN film and (b) a sapphire substrate after 30 min nitridation in $P_{\mathrm{NH}_{3}}=0.5 \mathrm{~atm}$.

was calculated from the XPS peak area divided by the corresponding atomic sensitivity factor (ASF) and normalized with the $\mathrm{Al} 2 p$ peak area. The $\mathrm{Al} 2 p$ peak was commonly used as a reference in sapphire nitridation studies ${ }^{4,11-19}$ since the vapor pressure of aluminum containing species (e.g., $\mathrm{AlO}, \mathrm{Al}_{2} \mathrm{O}$, and $\mathrm{Al}$ ) is negligible at $1100^{\circ} \mathrm{C} .{ }^{24}$ The concentration of surface aluminum atoms was assumed therefore to be approximately constant before and after nitridation. The ASF applied here were: 0.185 for $\mathrm{Al} 2 p, 0.42$ for $\mathrm{N} 1 s$, and 0.66 for $\mathrm{O} 1 s .{ }^{25}$ To investigate the depth profile of the chemical species, the takeoff angle was varied between $30^{\circ}$ to $90^{\circ}$ in order to change the photoelectron escape depth.

After nitridation, RHEED was used to examine surface structure of sapphire. The sapphire surface morphology was characterized using a tapping mode AFM. AFM data were taken from multiple locations on several samples after each nitridation run and the representative image is shown. The root-mean-square (rms) roughness reported here was determined from a 2 by $2 \mu \mathrm{m}^{2}$ scanning area from the average of multiple scans on a given set of nitridation conditions.

\section{RESULTS AND DISCUSSION}

The characterization of the nitridated surfaces were carried out ex situ. The impact and extent of air exposure on the nature and extent of the surface reaction was carefully determined. Controlled measurements of the air-exposed nitrided surfaces were used to correct for the observed changes in the surface chemistry. Ex situ measurements have been extensively used to study the nitridation process under different chemical processing conditions. , $^{2,3,7,10-12,15,18,23}$

\section{A. Normalized XPS intensities}

After nitridation at the specific values of time and $P_{\mathrm{NH}_{3}}$, the XPS spectra of all sapphire samples always contain a distinct $\mathrm{N} 1 s$ core-level photoelectron peak, indicating that nitrogen was incorporated into the sapphire surface. A typical $\mathrm{N} 1 s$ photoelectron peak from the nitridated sapphire surface is shown in Fig. 1 along with the N $1 s$ peak from a standard AlN film. In addition to the asymmetric shape of the $\mathrm{N} 1 s$ peak from the nitridated sapphire, a comparison with the 


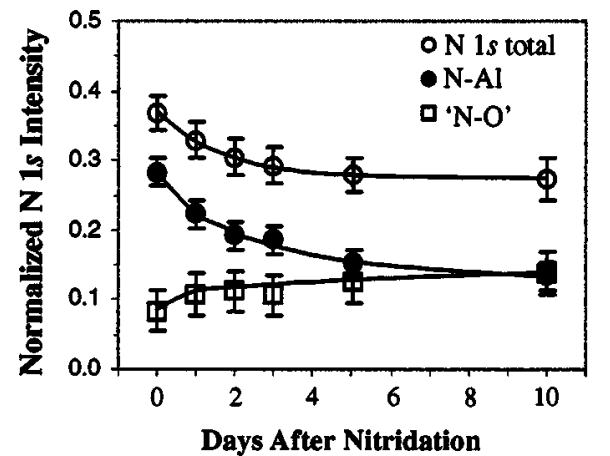

FIG. 2. Changes in the normalized $\mathrm{N} 1 s, \mathrm{~N}-\mathrm{Al}$, and ' $\mathrm{N}-\mathrm{O}$ ' peak intensities as a function of days after nitridation was performed (sample was nitridated in $P_{\mathrm{NH}_{3}}=0.5 \mathrm{~atm}$ for $30 \mathrm{~min}$ ). Changes in the nitrogen content of sapphire were caused by oxidation of the newly formed AlN layer by $\mathrm{O}_{2}$ and $\mathrm{H}_{2} \mathrm{O}$ in air.

$\mathrm{N} 1 s$ peak from the standard AlN film shows that the $\mathrm{N} 1 s$ peak from the nitridated sapphire originates from at least two different nitrogen chemical bonding states. The $\mathrm{N} 1 s$ peak was deconvoluted into two Gaussian peaks. The first peak at a binding energy of $\sim 396.7 \mathrm{eV}$ is attributed to $\mathrm{N}-\mathrm{Al}$ bonds since its binding energy coincides with the $\mathrm{N} 1 s$ binding energy from the standard AlN film. The second peak shifts to a higher energy at $\sim 398.0 \mathrm{eV}$ indicating that nitrogen is in oxygen-rich environment, since $\mathrm{O}$ is more electronegative than Al. This peak is due to incomplete substitutions of $\mathrm{O}$ by $\mathrm{N}$, so that some of the nearest neighboring $\mathrm{Al}$ atoms are still bonded to $\mathrm{O}$. In this article, this peak is labeled as ' $\mathrm{N}-\mathrm{O}$ '. The exact bonding state of this peak is still not understood. Past XPS studies of AIN powders ${ }^{26-28}$ did not attribute this peak to aluminum oxynitride spinel compound since the $\mathrm{N} 1 s$ binding energy in aluminum oxynitride spinel was reported to occur at $\sim 6.5 \mathrm{eV}$ higher than the $\mathrm{N}-\mathrm{Al}$ peak binding energy. ${ }^{29}$ These studies suggested that this peak might originate from a complex intermediate bonding state involving $\mathrm{Al}, \mathrm{N}$, and $\mathrm{O}$.

The XPS spectra clearly show that AlN is formed on the sapphire surface. Since the XPS characterization was done $e x$ situ, the newly formed AIN layer would be oxidized during transfer in air. Oxidation is thermodynamically favorable according to reactions:

$$
\begin{aligned}
& 2 \mathrm{AlN}+\frac{3}{2} \mathrm{O}_{2} \Leftrightarrow \mathrm{Al}_{2} \mathrm{O}_{3}+\mathrm{N}_{2}, \\
& 2 \mathrm{AlN}+3 \mathrm{H}_{2} \mathrm{O} \Leftrightarrow \mathrm{Al}_{2} \mathrm{O}_{3}+\mathrm{N}_{2}+3 \mathrm{H}_{2} .
\end{aligned}
$$

The Gibbs free energies $(\Delta G)$ at room temperature for oxidation reaction Eqs. (1) and (2) is -504 and $-161 \mathrm{~kJ}$ per mole of AlN, respectively. Oxidation of the newly formed AlN layer has to be taken into account when analyzing the XPS data in order to have an accurate interpretation of the data. The $\mathrm{N} 1 s$ peak of the nitridated sapphire was measured by an ex situ XPS day-by-day after nitridation to gauge the effect of oxidation on the nitrogen content of the sample. The $\mathrm{N} 1 s$ peak was deconvoluted into $\mathrm{N}-\mathrm{Al}$ and $\mathrm{N}-\mathrm{O}$ peaks and plotted as a function of days after nitridation in Fig. 2. The total $\mathrm{N} 1 s$ intensity decreases as the oxidation proceeds. The $\mathrm{N}-\mathrm{Al}$ intensity decreases rapidly during the first day and continues to decrease until it stays approximately constant

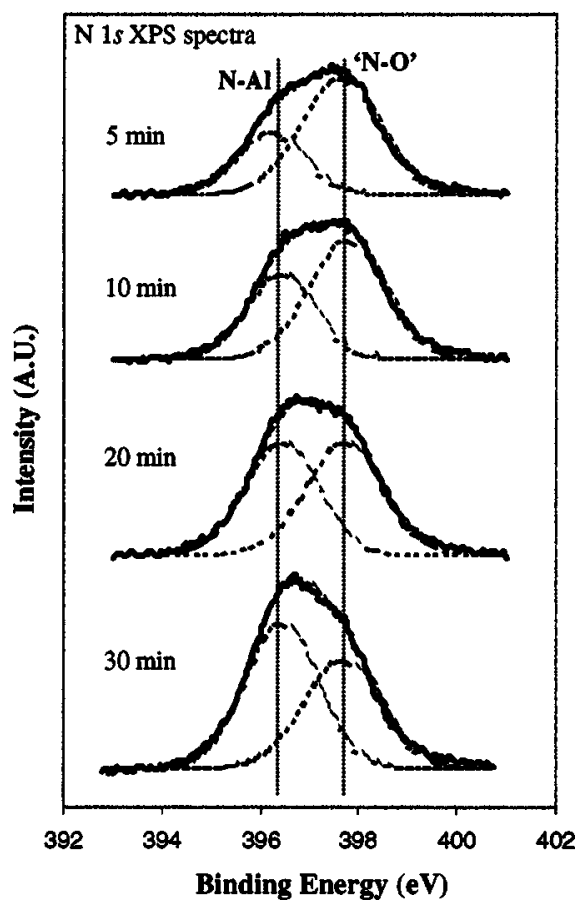

FIG. 3. Evolution of the $\mathrm{N} 1 s$ peak with nitridation time $\left(P_{\mathrm{NH}_{3}}\right.$ $=0.2 \mathrm{~atm})$. The $\mathrm{N}-\mathrm{Al}$ peak intensity increases as the nitridation proceeds.

after the fifth day. In contrast, the ' $\mathrm{N}-\mathrm{O}$ ' intensity slightly increases in the beginning and approaches a constant value after the third day. In this study, the ex situ XPS measurement of the samples were performed on the first or second day after the nitridation was carried out. In order to closely reflect the nitrogen content of the sapphire surface directly after nitridation, the $\mathrm{N}-\mathrm{Al}$ and ' $\mathrm{N}-\mathrm{O}$ ' peak intensities from the XPS spectra taken on the first or second day after nitridation were adjusted using data from Fig. 2 to their "zerotime" estimation. The $\mathrm{N}-\mathrm{Al}$ and ' $\mathrm{N}-\mathrm{O}$ ' peak intensities, measured on the first day after nitridation, were multiplied by 1.27 and 0.79 , respectively, to minimize the effect of oxidation of the nitridated layer during transfer in air. The $\mathrm{N}-\mathrm{Al}$ and ' $\mathrm{N}-\mathrm{O}$ ' peak intensities, measured on the second day, were multiplied by 1.47 and 0.75 , respectively. Each data point in Fig. 2 was collected from at least three samples and all samples showed consistent results. Samples that were measured on the first and second day and then scaled by fixed factors were compared with samples that were measured immediately after the nitridation. The results were the same and consistent every time. The rest of the data presented in this study were adjusted to their zero-time estimation and are simply called the "normalized" XPS intensities.

The $\mathrm{N} 1 s$ peak changes shape as the nitridation time increases as shown in Fig. 3 for nitridated sapphire in $P_{\mathrm{NH}_{3}}$ $=0.2 \mathrm{~atm}$. As expected, the $\mathrm{N}-\mathrm{Al}$ intensity increases as the nitridation proceeds. A similar trend was observed for nitridated sapphire in $P_{\mathrm{NH}_{3}}=0.5$ and $1.0 \mathrm{~atm}$. No measurable chemical shift could be observed in the $\mathrm{Al} 2 p$ or $\mathrm{O} 1 s$ peak binding energy from the nitridated sample, when compared to the $\mathrm{Al} 2 p$ or $\mathrm{O} 1 s$ peak from a clean $\mathrm{Al}_{2} \mathrm{O}_{3}$ substrate. The chemical shift cannot be observed since the binding energy difference between $\mathrm{Al}-\mathrm{N}$ and $\mathrm{Al}-\mathrm{O}$ or between $\mathrm{O}-\mathrm{Al}$ and 


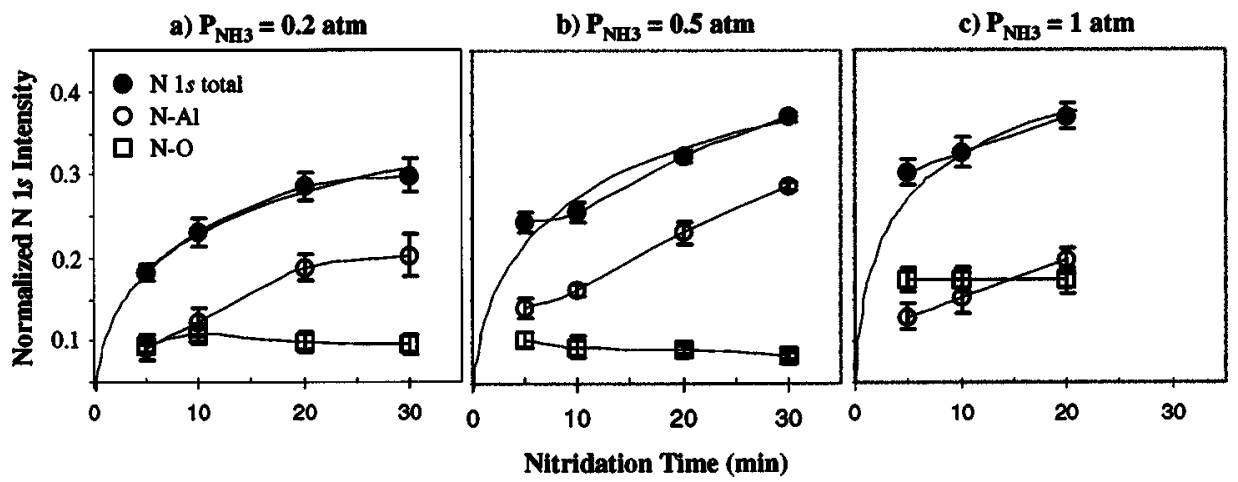

FIG. 4. Normalized $\mathrm{N} 1 s, \mathrm{~N}-\mathrm{Al}$, and $\mathrm{N}-\mathrm{O}$ peak intensities as a function of nitridation time. The nitridation was carried out using $P_{\mathrm{NH}_{3}}$ : (a) $0.2 \mathrm{~atm}$, (b) $0.5 \mathrm{~atm}$, and (c) $1.0 \mathrm{~atm}$. Solid lines are the calculated curve fitting using solution to the diffusion equation.

$\mathrm{O}-\mathrm{N}$ bonds is less than $0.5 \mathrm{eV}$, which is less than the resolution of our XPS system. However, the FWHM of the Al $2 p$ and $\mathrm{O} 1 s$ peaks increase with nitridation time indicating the occurrence of new $\mathrm{Al}$ and $\mathrm{O}$ bonding states that are close in binding energy to the $\mathrm{Al}-\mathrm{O}$ peak.

Figure 4 shows the normalized $\mathrm{N} 1 s$ peaks as a function of nitridation time for $P_{\mathrm{NH}_{3}}=0.2,0.5$, and $1.0 \mathrm{~atm}$. At the takeoff angle of $45^{\circ}$, the calculated maximum probing depth for the $\mathrm{N} 1 s$ signal in a matrix of $\mathrm{AlN}$ and $\mathrm{Al}_{2} \mathrm{O}_{3}$ is $\sim 6 \mathrm{~nm}$. Therefore, nitrogen-containing layers deeper than $\sim 6 \mathrm{~nm}$ do not contribute to the $\mathrm{N} 1 s$ total intensity. In general, the $\mathrm{N} 1 s$ intensity from the nitridated sapphire increases with nitridation time as well as with $P_{\mathrm{NH}_{3}}$. For each $P_{\mathrm{NH}_{3}}$ value, the $\mathrm{N}-\mathrm{Al}$ intensity increases as well with nitridation time, while the ' $\mathrm{N}-\mathrm{O}$ ' intensity remains approximately constant with nitridation time. The intensity of the $\mathrm{N} 1 s$ peak is higher after nitridation in $P_{\mathrm{NH}_{3}}=1.0 \mathrm{~atm}$ compared to nitridation in lower $P_{\mathrm{NH}_{3}}$ values. The value of ' $\mathrm{N}-\mathrm{O}$ ' intensity at $P_{\mathrm{NH}_{3}}$ $=0.2 \mathrm{~atm}$ is slightly larger than the value at $P_{\mathrm{NH}_{3}}$ $=0.5 \mathrm{~atm}$. At $P_{\mathrm{NH}_{3}}=1.0 \mathrm{~atm}$, the ' $\mathrm{N}-\mathrm{O}$ ' intensity is $\sim 1.8$ times higher when compared to the ' $\mathrm{N}-\mathrm{O}$ ' intensity at $P_{\mathrm{NH}_{3}}=0.5$ atm.

The normalized $\mathrm{O} 1 \mathrm{~s}$ photoelectron peaks as a function of nitridation time for $P_{\mathrm{NH}_{3}}=0.2,0.5$, and 1.0 atm are shown in Fig. 5. At each $P_{\mathrm{NH}_{3}}$ value, the $\mathrm{O} 1 s$ intensity from the sapphire surface decreases with nitridation time, which is in an opposite trend to the $\mathrm{N} 1 s$ signal. When comparing the $\mathrm{O} 1 s$ intensity between each $P_{\mathrm{NH}_{3}}$ value, the overall intensity follows the general trend of the ' $\mathrm{N}-\mathrm{O}$ ' signal, i.e., the $\mathrm{O} 1 s$ intensity is the lowest at $P_{\mathrm{NH}_{3}}=0.5 \mathrm{~atm}$ and the highest at

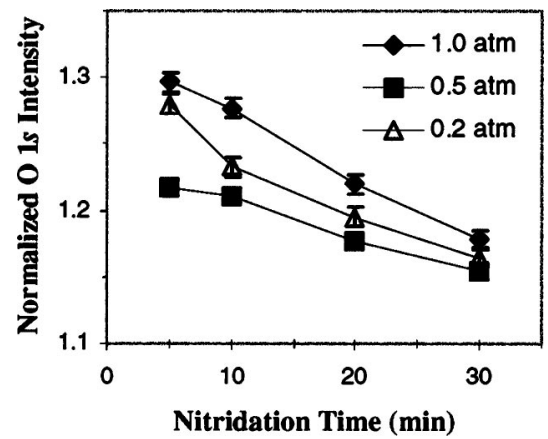

FIG. 5. Normalized O $1 s$ peak intensity as a function of nitridation time for $P_{\mathrm{NH}_{3}}=0.2,0.5$, and $1.0 \mathrm{~atm}$. The solid line is a guide for the eye.
$P_{\mathrm{NH}_{3}}=1.0$ atm. This general correlation between the $\mathrm{O} 1 \mathrm{~s}$ and $\mathrm{N}-\mathrm{O}$ signal supports the idea that the $\mathrm{N}-\mathrm{O}$ peak originates from nitrogen in an oxygen-rich environment.

\section{B. Angle-resolved XPS}

The depth profiles of the nitrogen and oxygen species were established through the measurements of XPS spectra at different takeoff angles from $\theta=30^{\circ}$ to $90^{\circ} .{ }^{30}$ The smaller takeoff angle leads to a more surface sensitive measurement. Figure 6 shows the normalized $\mathrm{N} 1 s, \mathrm{~N}-\mathrm{Al}$, 'N-O', and $\mathrm{O} 1 s$ peak intensities as a function of the takeoff angle after 60 min nitridation in $P_{\mathrm{NH}_{3}}=0.2$ atm. As $\theta$ increases, the $\mathrm{N} 1 s$ and $\mathrm{N}-\mathrm{Al}$ depth profiles initially decrease before finally increasing at $\theta=90^{\circ}$, while the 'N-O' depth profile is approximately constant. The $\mathrm{O} 1 s$ depth profile has an opposite trend to the $\mathrm{N} 1 s$ and $\mathrm{N}-\mathrm{Al}$ depth profiles, i.e., when the $\mathrm{N} 1 s$ and $\mathrm{N}-\mathrm{Al}$ intensities decrease, the $\mathrm{O} 1 s$ intensity increases. Similar nitrogen and oxygen depth profiles were observed at other samples with different nitridation time and $P_{\mathrm{NH}_{3}}$ value.

As with any normalization procedure, some caution must be exercised. in the data analysis employed here, the depth profile data, i.e., the $\mathrm{N} 1 s$ and $\mathrm{O} 1 s$ intensities, since at each takeoff angle, the $\mathrm{N} 1 s$ and $\mathrm{O} 1 s$ intensities were normalized with the Al $2 p$ intensity at that angle. ${ }^{30,31}$ The Al $2 p$ peak is

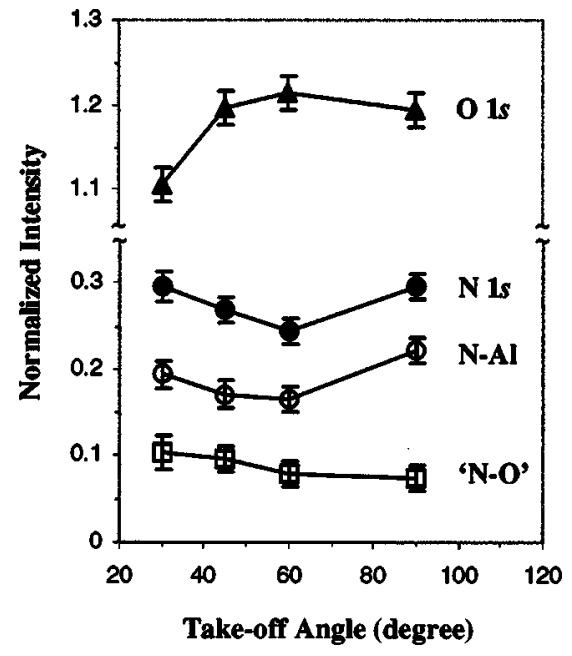

FIG. 6. Normalized N $1 s, \mathrm{~N}-\mathrm{Al}$, 'N-O', and $\mathrm{O} 1 s$ peak intensities after 60 min nitridation in $P_{\mathrm{NH}_{3}}=0.2 \mathrm{~atm}$ as a function of the photoelectron takeoff angle. 
commonly used as reference for other elemental peaks in previous nitridation studies. ${ }^{4,11-19}$ The $\mathrm{Al} 2 p$ peak serves as a reference since the vapor pressure of aluminum containing species, e.g., $\mathrm{AlO}, \mathrm{Al}_{2} \mathrm{O}$, and $\mathrm{Al}$, is negligible at $1100^{\circ} \mathrm{C}$. Thus, the concentration or total amount of surface aluminum atoms were considered constant before and after nitridation. The $\mathrm{Al}$ atoms can be reasonable assumed to be uniform in depth since the as-received sapphire surface was extremely smooth possessing no observable defects and possessing a measured rms roughness of $\sim 2.4 \mathrm{~nm}$. Previous TEM-based studies have indicated that the nitridated sapphire is defectfree and leading to the inference that the distribution of $\mathrm{Al}$ atoms is lateral uniform. ${ }^{4,8,13}$ The difference of $\mathrm{Al} 2 p$ photoelectron escape depth relative to $\mathrm{N} 1 s$ and $\mathrm{O} 1 s$ photoelectron escape depths can affect the attenuation of the photoelectron signal as the takeoff angle increases. We have accounted for these changes in our subsequent analyses using electron escape depths obtained from a report by Powell. ${ }^{32}$ The results of the analyses are dependent on the choice of escape depths. Other values of escape depth derived from other reports or databases ${ }^{33}$ will alter the results presented. The reported uncertainty in our results reflect, in part, the uncertainty in the reported electron escape depths.

One interpretation of the nitrogen depth profile is that there was a segregation of nitrogen in sapphire. The nitrogen segregates into a thin AlN layer on the surface $(<6 \mathrm{~nm})$ and deeper into the sapphire. The elementary steps of diffusion are only possible because of the existence of lattice defects. A crystal may contain point defects and dislocations. The most important lattice defects in connection with diffusion are point defects. The literature on atomic mechanisms of anion diffusion in sapphire or AlN is very limited and has conflicting results. ${ }^{34,35}$ Based on the experimental data from the present study, it is not possible to predict the atomic diffusion mechanism of nitrogen and oxygen in sapphire and in AlN. The segregation of nitrogen deeper into the sapphire may be due to the presence of misfit dislocations as sapphire and AlN has $\sim 3 \%$ lattice mismatch. Dislocations can serve as a path for rapid diffusion. ${ }^{36}$ More investigation is needed to determine the cause of nitrogen segregation.

\section{RHEED patterns}

Following $30 \mathrm{~min}$ nitridation in $P_{\mathrm{NH}_{3}}=0.5 \mathrm{~atm}$, the sample was immediately transferred to a RHEED chamber in order to minimize reoxidation effect on the surface structure. Figure 7 shows the RHEED patterns of the sapphire surface before and after nitridation at two azimuthal angles: $\langle 11 \overline{2} 0\rangle$ and $\langle 10 \overline{1} 0\rangle$. The streaky RHEED patterns show that the nitrogen-containing layer is crystalline. The in-plane lattice constant of the surface layer can be calculated from the RHEED streak distance, which is $\sim 0.31 \mathrm{~nm}$. This value corresponds to the AlN lattice parameter $(a=0.3111 \mathrm{~nm}){ }^{37}$ Thus, the RHEED patterns verify that the sapphire surface is converted into an AlN layer after nitridation. The in-plane direction of the AlN layer is rotated $30^{\circ}$ with respect to the sapphire direction, such that $[0002]_{\mathrm{AIN}} \|[0002]_{\text {sapphire }}$ and $[11 \overline{2} 0]_{\text {AIN }} \|[1 \overline{1} 00]_{\text {sapphire }}$. The $30^{\circ}$ rotation between the AIN
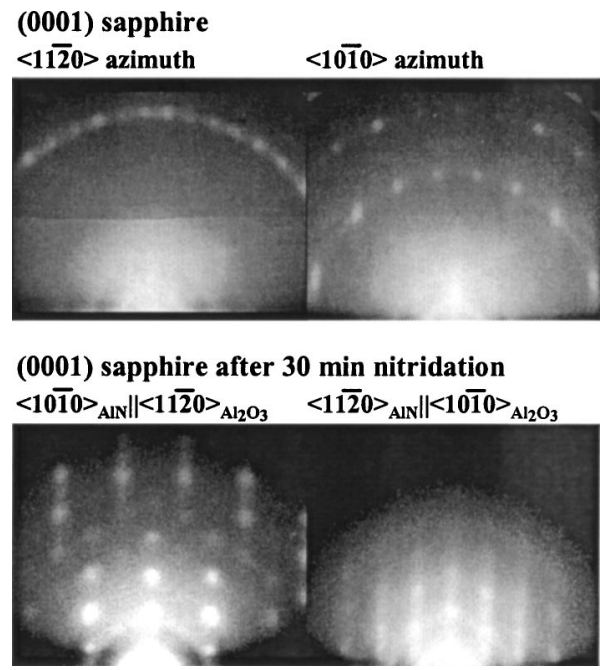

FIG. 7. RHEED patterns of the (0002) sapphire surface before and after 30 min nitridation in $P_{\mathrm{NH}_{3}}=0.5 \mathrm{~atm}$. After nitridation, an imperfect AlN layer is formed on the surface with a $30^{\circ}$ rotation of the in-plane lattice direction with respect to the same direction in sapphire.

layer and the sapphire substrate is typical for epitaxial growth of AlN on sapphire in order to minimize the lattice mismatch between the two lattices.

\section{Proposed nitridation mechanism}

The N $1 s$ peak was not observed after exposure to only $\mathrm{N}_{2}$ at $1100^{\circ} \mathrm{C}$ for $30 \mathrm{~min}$. Thus, the incorporated nitrogen in the sapphire surface is caused only by interactions between $\mathrm{NH}_{3}$ with sapphire. At $1100^{\circ} \mathrm{C}$, a reaction between $\mathrm{Al}_{2} \mathrm{O}_{3}$ and $\mathrm{N}_{2}$ has a large thermodynamic barrier $\left(\Delta G_{1100^{\circ} \mathrm{C}}\right.$ $\sim 900 \mathrm{~kJ} / \mathrm{mol} \mathrm{Al}_{2} \mathrm{O}_{3}$ ). Also, a previous study reported that a reaction between sapphire and $\mathrm{N}_{2}$ only occurred at temperatures greater than $1200^{\circ} \mathrm{C} .{ }^{38}$

The sapphire nitridation process starts with the adsorption of $\mathrm{NH}_{3}$ molecules onto the sapphire surface. Although $\mathrm{NH}_{3}$ is thermodynamically unstable at $1100^{\circ} \mathrm{C}$, its homogeneous gas-phase decomposition to $\mathrm{N}_{2}$ and $\mathrm{H}_{2}$ is kinetically very slow so that most of $\mathrm{NH}_{3}$ remains intact and can adsorb on the surface. ${ }^{39}$ At high temperatures $\left(>300{ }^{\circ} \mathrm{C}\right), \mathrm{NH}_{3}$ adsorbs dissociatively on sapphire surface according to: $:^{40,41}$

$$
\mathrm{NH}_{3} \Leftrightarrow \mathrm{NH}_{x(\mathrm{a})}+(3-x) \mathrm{H}_{(\mathrm{a})} .
$$

Studies of $\mathrm{NH}_{3}$ adsorption on various surfaces have observed that as temperature increased, the rate of $\mathrm{NH}_{3}$ dehydrogenation increased such that eventually only nitrogen atoms were left on the surface. ${ }^{42-44}$ A complete dehydrogenation on these various surfaces takes place at $\sim 500{ }^{\circ} \mathrm{C}$. In the present study, it is therefore reasonable to assume that at $1100{ }^{\circ} \mathrm{C}$, most of the adsorbed $\mathrm{NH}_{3}$ on sapphire undergoes a complete dehydrogenation leaving only adsorbed nitrogen atoms on the surface. Some hydrogen atoms recombine and desorb from the surface as $\mathrm{H}_{2}$ and some hydrogen atoms may combine with oxygen, which is diffusing out from the sapphire, and desorb as $\mathrm{H}_{2} \mathrm{O}$.

Some of the adsorbed nitrogen atoms diffuse into the sapphire and react with the network of aluminum and oxygen atoms. The diffused nitrogen substitutes for oxygen to bond 


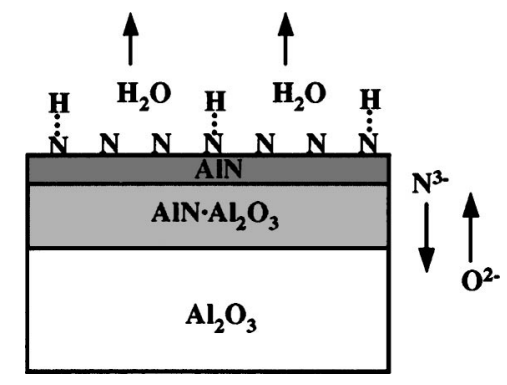

FIG. 8. Illustration of the sapphire nitridation process. First, $\mathrm{NH}_{3}$ adsorbs dissociatively on sapphire until only $\mathrm{N}$ remains on the surface at $1100{ }^{\circ} \mathrm{C}$. Then, an AlN layer is formed on the surface. The nitridation process can be modeled as a diffusion couple of $\mathrm{AlN}$ and $\mathrm{Al}_{2} \mathrm{O}_{3}$. The exchange involves anions $\left(\mathrm{N}^{3-}\right.$ and $\left.\mathrm{O}^{2-}\right)$ in the rigid cation $\left(\mathrm{Al}^{3+}\right)$ framework. Oxygen atoms, which are substituted by nitrogen, diffuse out to the surface, and then combine with hydrogen and desorb as $\mathrm{H}_{2} \mathrm{O}$.

with aluminum as indicated by the presence of $\mathrm{N}-\mathrm{Al}$ XPS peaks. Oxygen substitution by nitrogen progresses with time as indicated by the increase in $\mathrm{N}-\mathrm{Al}$ intensity with nitridation time. This substitution is still incomplete after nitridation for up to $60 \mathrm{~min}$, as indicated by the presence of the 'N-O' peak. Other nitridation studies also suggested that oxygen atoms still remain in the nitridated layer., ${ }^{4,8}$ The bond substitution is accompanied by structural change as the RHEED patterns show that the AIN in-plane direction is rotated $30^{\circ}$ with respect to the sapphire direction.

The proposed nitridation mechanism draws an analogy from the formation of spinel compounds, such as $\mathrm{MgAl}_{2} \mathrm{O}_{4} \cdot{ }^{45}$ In the spinel formation, the cations counterdiffuse through a constant anion network. On the other hand, the sapphire nitridation mechanism involves the counterdiffusion of anions $\left(\mathrm{N}^{3-}\right.$ and $\left.\mathrm{O}^{2-}\right)$ in the rigid cation $\left(\mathrm{Al}^{3+}\right)$ framework. Figure 8 illustrates a schematic diagram for the sapphire nitridation process, which can be modeled as a diffusion couple of $\mathrm{AlN}$ and $\mathrm{Al}_{2} \mathrm{O}_{3}$. A thin AlN layer is formed on the surface in the first few minutes of nitridation and is maintained throughout the process due to a constant supply of nitrogen on the surface. Nitrogen diffusion in sapphire is coupled to and complicated by the outward diffusion of the replaced oxygen. This coupling maintains local electroneutrality during diffusion. Oxygen atoms, which are substituted by nitrogen, must diffuse out to the surface, and then combine with hydrogen and desorb as $\mathrm{H}_{2} \mathrm{O}$, according to the overall nitridation reaction:

$$
\mathrm{Al}_{2} \mathrm{O}_{3}+2 \mathrm{NH}_{3} \Leftrightarrow 2 \mathrm{AlN}+3 \mathrm{H}_{2} \mathrm{O} \text {. }
$$

Oxygen transport to the surface and its subsequent desorption lead to the decrease of surface oxygen content as shown in Fig. 5, where the $\mathrm{O} 1 s$ intensity decreases with nitridation time. The same observation was reported in nitridation studies of sapphire and $\mathrm{SiO}_{2} \cdot{ }^{15,46}$ The overall nitridation rate is determined by the slower of the diffusion process, which can be the inward diffusion of nitrogen or the outward diffusion of oxygen. It should be noted that since the nitridated sapphire layer is extremely thin (only a few monolayers), there might be in-plane nonuniformities. Both in-plane nonunifor- mities as well as the very thin-film nature of the reacted layer will impact the range of validity of any simple interdiffusionreaction model.

\section{E. XPS data fitting}

In the present study, the chemical diffusion coefficient of nitrogen $\left(\widetilde{D}_{\mathrm{N}}\right)$ and the chemical diffusion coefficient of oxygen $\left(\widetilde{D}_{\mathrm{O}}\right)$ were estimated from the XPS data. The chemical diffusion coefficient of nitrogen (oxygen) does not represent an intrinsic diffusion coefficient of nitrogen (oxygen) in sapphire (AlN), but it describes the motion of nitrogen (oxygen) coupled to the motion of oxygen (nitrogen) in the $\mathrm{AlN}-\mathrm{Al}_{2} \mathrm{O}_{3}$ matrix. By assuming a sharp interface between the AlN layer and sapphire, the normalized N $1 s$ intensity can be fitted using the solution to the diffusion equation for a constant nitrogen concentration at the sapphire surface, $N_{\mathrm{N}_{0}}$. $N_{\mathrm{N}_{0}}$ is assumed to be constant at all times since $P_{\mathrm{NH}_{3}}$ was kept constant during the nitridation process. The solution to this diffusion equation leads to a time and distance dependence concentration profile for $\mathrm{N} 1 s$, which is given by:

$$
N_{\mathrm{N}}(z, t)=N_{\mathrm{N}_{0}} \times \operatorname{erfc}\left(\frac{z}{2 \sqrt{\widetilde{D}_{\mathrm{N}} t}}\right)
$$

where $z$ is the depth into the sapphire surface and $t$ is the diffusion time. The XPS area intensity of the $\mathrm{N} 1 s, I_{\mathrm{N}}$, is expressed by: ${ }^{25}$

$$
I_{\mathrm{N}}(z, t)=k \sigma_{\mathrm{N}} \int_{0}^{\infty} N_{\mathrm{N}}(z, t) \times \exp \left(-\frac{z}{\lambda_{\mathrm{N}} \sin \theta}\right) d z,
$$

where $k$ is the XPS apparatus constant, $\lambda_{\mathrm{N}}$ is the $\mathrm{N} 1 s$ electron escape depth, ${ }^{32} \sigma_{\mathrm{N}}$ is the photoionization cross section of $\mathrm{N}$, and $\theta$ is the photoelectron takeoff angle. The apparatus constant $k$, can be removed by normalizing Eq. (6) with the area intensity of $\mathrm{Al} 2 p, I_{\mathrm{Al}}$ :

$$
I_{\mathrm{Al}}=k \sigma_{\mathrm{Al}} N_{\mathrm{Al}} \lambda_{\mathrm{Al}} \sin \theta,
$$

where $N_{\mathrm{Al}}$ is the $\mathrm{Al}$ concentration in sapphire, assumed to be constant, $\lambda_{\mathrm{Al}}$ is the $\mathrm{Al} 2 p$ electron escape depth, ${ }^{46}$ and $\sigma_{\mathrm{Al}}$ is the photoionization cross section of Al. The solution of Eq. (6) yields the normalized area intensity of $\mathrm{N} 1 s$ peak, $I_{\mathrm{N}, \text { norm }}$, which is given by:

$$
\begin{aligned}
I_{\mathrm{N}, \text { norm }}(t)= & \frac{I_{\mathrm{N}}}{I_{\mathrm{Al}}}=\frac{\sigma_{\mathrm{N}} \lambda_{\mathrm{N}} N_{\mathrm{N}_{0}}}{\sigma_{\mathrm{Al}} \lambda_{\mathrm{Al}} N_{\mathrm{Al}}}\left[1-\exp \left(\frac{\widetilde{D}_{\mathrm{N}} t}{\lambda_{\mathrm{N}}^{2} \sin ^{2} \theta}\right)\right. \\
& \left.\times \operatorname{erfc}\left(\frac{\sqrt{\widetilde{D}_{\mathrm{N}} t}}{\lambda_{\mathrm{N}} \sin \theta}\right)\right] .
\end{aligned}
$$

Equation (8) was used to fit the XPS data with parameter constants as follows: $\sigma_{\mathrm{N}}=1.77, \sigma_{\mathrm{Al}}=0.5735, \lambda_{\mathrm{N}} \sim 2.4 \mathrm{~nm}$, $\lambda_{\mathrm{Al}} \sim 3.0 \mathrm{~nm},{ }^{32} \theta=45^{\circ}$, and $N_{\mathrm{Al}}$ is calculated from sapphire density to be $4.49 \times 10^{22} \mathrm{~cm}^{-3}$. The electron escape depths were obtained from a report by Powell, which addressed the escape depth dependence on material. ${ }^{32}$ The independent variable is $t$ and the fitting parameters are $\widetilde{D}_{\mathrm{N}}$ and $N_{\mathrm{N}_{0}}$. The fitting is shown in Fig. 4. $\widetilde{D}_{\mathrm{O}}$ can be estimated by plotting the normalized intensity of oxygen leaving the surface as a func- 


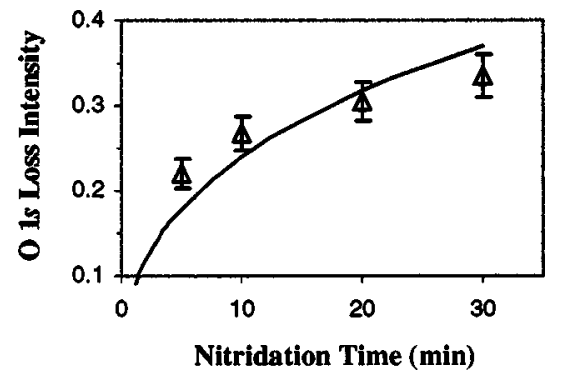

FIG. 9. Oxygen loss from the sapphire surface as a function of nitridation time for $P_{\mathrm{NH}_{3}}=0.2 \mathrm{~atm}$. The oxygen loss was calculated by subtracting the normalized $\mathrm{O} 1 s$ intensity from 1.5 (the normalized $\mathrm{O} 1 s$ intensity of asreceived sapphire). The solid line is the calculated curve fitting using solution to the diffusion equation.

tion of time as shown in Fig. 9. The normalized intensity of oxygen leaving the surface is just the as-received normalized $\mathrm{O} 1 s$ intensity $(=1.5)$ minus the nitridated sapphire normalized O $1 s$ intensity. Then Eq. (8) can be used to fit the plot in Fig. 9 after substituting the subscript $\mathrm{N}$ with $\mathrm{O}$ for oxygen. The parameter constants for oxygen are as follows: $\sigma_{\mathrm{O}}$ $=2.85$ and $\lambda_{\mathrm{O}} \sim 2.1 \mathrm{~nm} .{ }^{32,47}$ The fitting parameter is $\widetilde{D}_{\mathrm{O}}$ only, since $N_{\mathrm{O}_{0}}$ is calculated from the sapphire density to be $\sim 7.05 \times 10^{22} \mathrm{~cm}^{-3}$.

The fitting results are summarized in Table I. The calculated $\widetilde{D}_{\mathrm{N}}, \widetilde{D}_{\mathrm{O}}$, and $N_{\mathrm{N}_{0}}$ values in the present study should be considered to have a one-order-of-magnitude accuracy given in the uncertainty in the model assumptions and the possible range of electron escape depths. Again, the value of $N_{\mathrm{O}_{0}}$ is assumed constant and hence not presented in the table. Compared to the values in literature, $\widetilde{D}_{\mathrm{N}}$ and $\widetilde{D}_{\mathrm{O}}$ obtained in the present study differ by one to three orders of magnitude depending on the experimental setup (e.g., nitrogen source, material crystallinity, pressure, etc.). ${ }^{18,48,49}$ The estimated values of $\widetilde{D}_{\mathrm{N}}$ are consistently higher than $\widetilde{D}_{\mathrm{O}}$ at each $P_{\mathrm{NH}_{3}}$ value. This result suggests that the overall nitridation rate is controlled by the diffusion of oxygen to the surface. The $\mathrm{N}-\mathrm{Al}$ intensity of the nitridated sapphire is also mainly determined by the outward diffusion of oxygen and not by the inward diffusion of nitrogen. At $P_{\mathrm{NH}_{3}}=1.0 \mathrm{~atm}, \widetilde{D}_{\mathrm{N}}$ is $\sim 3 \times$ higher but $\widetilde{D}_{\mathrm{O}}$ is $\sim 0.8 \times$ lower compared to $\widetilde{D}_{\mathrm{N}}$ and $\widetilde{D}_{\mathrm{O}}$ at $P_{\mathrm{NH}_{3}}$ $=0.2$ and 0.5 atm. This slightly lower $\widetilde{D}_{\mathrm{O}}$ value at $P_{\mathrm{NH}_{3}}$ $=1.0 \mathrm{~atm}$ results in the lowest $\mathrm{N}-\mathrm{Al}$ intensity even though the overall $\mathrm{N} 1 s$ intensity is the highest compared to the intensity at $P_{\mathrm{NH}_{3}}=0.2$ and $0.5 \mathrm{~atm}$.

TABLE I. Results of XPS data fitting to obtain the diffusion coefficients.

\begin{tabular}{cccc}
\hline \hline $\begin{array}{c}\mathrm{P}_{\mathrm{NH}_{3}} \\
(\mathrm{~atm})\end{array}$ & $N_{\mathrm{N}_{0}}\left(\mathrm{~cm}^{-3}\right)$ & $\begin{array}{c}\widetilde{D}_{\mathrm{N}} \\
\left(\mathrm{cm}^{2} / \mathrm{s}\right)\end{array}$ & $\begin{array}{c}\widetilde{D}_{\mathrm{O}} \\
\left(\mathrm{cm}^{2} / \mathrm{s}\right)\end{array}$ \\
\hline 0.2 & $\sim 2.1 \times 10^{22}$ & $\sim 1 \times 10^{-15}$ & $\sim 1 \times 10^{-16}$ \\
0.5 & $\sim 2.5 \times 10^{22}$ & $\sim 1 \times 10^{-15}$ & $\sim 1 \times 10^{-16}$ \\
1.0 & $\sim 2.3 \times 10^{22}$ & $\sim 3 \times 10^{-15}$ & $\sim 8 \times 10^{-17}$ \\
\hline \hline
\end{tabular}
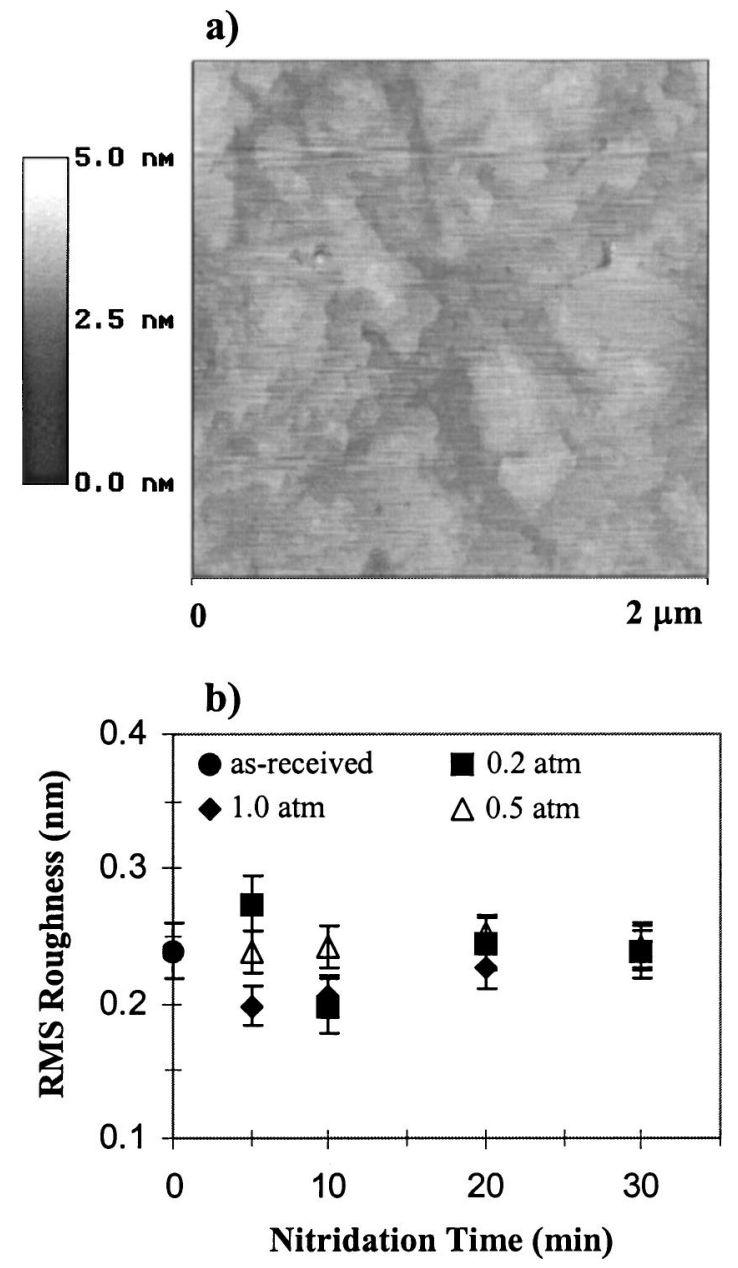

FIG. 10. (a) AFM image of sapphire surface after 30 min nitridation in $P_{\mathrm{NH}_{3}}=0.5 \mathrm{~atm}$. No protrusions are observed on the surface, (b) rms roughness of as-received sapphire and nitridated sapphire as a function of nitridation time in $P_{\mathrm{NH}_{3}}=0.2,0.5$, and $1.0 \mathrm{~atm}$.

\section{F. Surface morphology}

Figure 10(a) shows an AFM image of the sapphire surface after 30 min nitridation in $P_{\mathrm{NH}_{3}}=0.5 \mathrm{~atm}$. No protrusions are observed on the surface and the rms roughness is $\sim 0.24 \mathrm{~nm}$, which is comparable to the rms roughness of the as-received sapphire. Even when nitridation was continued to $60 \mathrm{~min}$, no protrusions are observed on the surface. Figure 10(b) shows a comparison of the surface rms roughness between the as-received sapphire and sapphire after nitridation in $P_{\mathrm{NH}_{3}}=0.2,0.5$, and $1.0 \mathrm{~atm}$ as a function of nitridation time. No significant changes in the rms roughness are observed for all nitridated samples when compare to the asreceived sapphire.

The surface morphology of sapphire after nitridation is relatively unchanged as compared to the as-received sapphire, which is contrary to the results obtained in MOVPE $^{2,7,12}$ and MBE with a rf nitrogen plasma ${ }^{19-22}$ and a constricted-plasma ${ }^{18}$ source. In these studies, high densities of protrusions were observed on the surface. Uchida et al. considered that the protrusions were originated from the relaxation of excess strain due to the large lattice mismatch between the nitridated layer and sapphire. ${ }^{2}$ Such protrusions 
were not observed in our study implying that there is no strain built up in the AlN layer. The strain relaxation pathway could be provided by an incomplete transformation of AlN, i.e., ' $\mathrm{N}-\mathrm{O}$ ' bonds in the AlN layer. In addition, a $\mathrm{NH}_{3}$ and $\mathrm{N}_{2}$ nitridation source used under HVPE condition may not be as reactive toward sapphire when compared to a $\mathrm{NH}_{3}$ and $\mathrm{H}_{2}$ source used within the MOVPE environment or a nitrogen plasma source used in MBE, so that sapphire surface morphology is unchanged. A more reactive nitridation source can result in a faster and complete transformation from sapphire to AlN layer, which contains excess strain. The excess strain is relaxed by forming protrusions on the surface.

\section{CONCLUSIONS}

The nitridation of $c$-plane sapphire within the HVPE system was systematically studied as a function of time and $P_{\mathrm{NH}_{3}}$ using ex situ XPS, RHEED, and AFM. Nitrogen was incorporated into the sapphire surface during the nitridation process. There were two identified nitrogen chemical bonding states, which are attributed to $\mathrm{N}-\mathrm{Al}$ bonds and nitrogen in oxygen-rich environment (' $\mathrm{N}-\mathrm{O}$ '). The $\mathrm{N} 1 s$ and $\mathrm{N}-\mathrm{Al}$ intensities increased, while the ' $\mathrm{N}-\mathrm{O}$ ' intensity remained approximately constant with nitridation time. The $\mathrm{O} 1 s$ intensity decreased with nitridation time indicating that oxygen was depleted from the near-surface region. The nitridation process starts with the dissociative adsorption of $\mathrm{NH}_{3}$ on sapphire surface. At $1100^{\circ} \mathrm{C}$, only nitrogen atoms remain on the surface. The adsorbed nitrogen atoms diffuse into the sapphire and react with the network of aluminum and oxygen atoms. The sapphire nitridation process was modeled as a diffusion couple of AlN and $\mathrm{Al}_{2} \mathrm{O}_{3}$, where $\mathrm{N}^{3-}$ and $\mathrm{O}^{2-}$ interdiffuse in the rigid $\mathrm{Al}^{3+}$ framework. Nitrogen diffuses into sapphire and substitutes for oxygen to bond with aluminum. The bond substitution is accompanied by structural change where the AlN in-plane direction is rotated $30^{\circ}$ with respect to the sapphire direction. The displaced oxygen atoms diffuse to the surface, combine with hydrogen, and desorb as $\mathrm{H}_{2} \mathrm{O}$. The overall nitridation rate was determined by the slower moving anions. From the XPS data, $\widetilde{D}_{\mathrm{N}}$ and $\widetilde{D}_{\mathrm{O}}$ were estimated. $\widetilde{D}_{\mathrm{N}}$ was consistently higher than $\widetilde{D}_{\mathrm{O}}$ at each $P_{\mathrm{NH}_{3}}$ value. This result suggested that the overall nitridation rate was controlled by the diffusion of oxygen to the surface. After nitridation, no surface protrusions were observed and no significant changes in the surface rms roughness were measured when compared to the as-received sapphire.

\section{ACKNOWLEDGMENTS}

The financial support of ONR (C. Wood) and DARPA is gratefully acknowledged. Additional facilities support was provided by the NSF-funded Materials Research Science and Engineering Center at University of Wisconsin-Madison.

\footnotetext{
${ }^{1}$ S. Keller, B. P. Kemmer, Y. F. Wu, B. Heyring, D. Kapolnek, J. S. Speck, U. K. Mishra, and S. P. DenBaars, Appl. Phys. Lett. 68, 1525 (1996).

${ }^{2}$ K. Uchida, A. Watanabe, F. Yano, M. Kouguchi, T. Tanaka, and S. Minagawa, J. Appl. Phys. 79, 3487 (1996).

${ }^{3}$ G. Namkoong, W. A. Doolittle, A. S. Brown, M. Losurdo, P. Capezzuto, and G. Bruno, J. Appl. Phys. 91, 2499 (2002).
}

${ }^{4}$ F. Widmann, G. Feuillet, B. Daudin, and J. L. Rouvière, J. Appl. Phys. 85, 1550 (1999).

${ }^{5}$ S. Gu, R. Zhang, Y. Shi, Y. Zheng, L. Zhang, F. Dwikusuma, and T. F. Kuech, J. Cryst. Growth 231, 342 (2001).

${ }^{6}$ R. J. Molnar, P. Maki, R. Aggarwal, Z. L. Liau, E. R. Brown, I. Melngailis, W. Gotz, L. T. Romano, and N. M. Johnson, Mater. Res. Soc. Symp. Proc. 423, 221 (1996).

${ }^{7}$ T. Hashimoto, Y. Terakoshi, M. Ishida, M. Yuri, O. Imafuji, T. Sugino, A. Yoshikawa, and K. Itoh, J. Cryst. Growth 189/190, 254 (1998).

${ }^{8}$ P. Vennéguès and B. Beaumont, Appl. Phys. Lett. 75, 4115 (1999).

${ }^{9}$ M. Seelmann-Eggebert, H. Zimmermann, H. Obloh, R. Niebuhr, and B. Wachtendorf, J. Vac. Sci. Technol. A 16, 2008 (1998).

${ }^{10}$ A. Yamamoto, M. Tsujino, M. Ohkubo, and A. Hashimoto, J. Cryst. Growth 137, 415 (1994).

${ }^{11}$ T. Hashimoto, Y. Terakoshi, M. Yuri, M. Ishida, O. Imafuji, T. Sugino, and K. Itoh, J. Appl. Phys. 86, 3670 (1999).

${ }^{12}$ T. Suetsugu, T. Yamazaki, S. Tomabechi, K. Wada, K. Masu, and K. Tsubouchi, Appl. Surf. Sci. 117/118, 540 (1997).

${ }^{13}$ N. Grandjean, J. Massies, Y. Martinez, P. Vennéguès, M. Leroux, and M. Laügt, J. Cryst. Growth 179, 220 (1997).

${ }^{14}$ M. Yeadon, M. T. Marshall, F. Hamdani, S. Pekin, H. Morkoç, and J. M. Gibson, J. Appl. Phys. 83, 2847 (1998).

${ }^{15}$ C. Heinlein, J. K. Grepstad, S. Einfeldt, D. Hommel, T. Berge, and A. P. Grande, J. Appl. Phys. 83, 6023 (1998).

${ }^{16}$ W. T. Taferner, A. Bensaoula, E. Kim, and A. Bousetta, J. Cryst. Growth 164, 167 (1996).

${ }^{17}$ K.-S. Kim, S.-H. Kim, and D.-R. Lee, Appl. Phys. Lett. 76, 1552 (2000).

${ }^{18}$ Y. Cho, Y. Kim, E. R. Weber, S. Ruvimov, and Z. Liliental-Weber, J. Appl. Phys. 85, 7909 (1999).

${ }^{19}$ C. Heinlein, J. Grepstad, T. Berge, and H. Riechert, Appl. Phys. Lett. 71, 341 (1997).

${ }^{20}$ J.-S. Paek, K.-K. Kim, J.-M. Lee, D.-J. Kim, M.-S. Yi, D. Y. Noh, H.-G. Kim, and S.-J. Park, J. Cryst. Growth 200, 55 (1999).

${ }^{21}$ S. Mikroulis, A. Georgakilas, A. Kostopoulos, V. Cimalla, E. Dimakis, and Ph. Komninou, Appl. Phys. Lett. 80, 2886 (2002).

${ }^{22}$ T. Tokuda, A. Wakahara, S. Noda, and A. Sasaki, J. Cryst. Growth 183, 62 (1998).

${ }^{23}$ M. Losurdo, P. Capezzuto, and G. Bruno, J. Appl. Phys. 88, 2138 (2000).

${ }^{24}$ L. Brewer and A. W. Searcy, J. Am. Chem. Soc. 73, 5308 (1951).

${ }^{25}$ Practical Surface Analysis by Auger and X-Ray Photoelectron Spectroscopy, edited by D. Briggs and M. P. Seah (Wiley, New York, 1983).

${ }^{26}$ N. Shashidhar and J. R. Varner, in Ceramic Powder Science III, edited by G. L. Messing, S. Hirano, and H. Hausner (American Ceramic Society, OH, 1990) p. 875.

${ }^{27}$ H. M. Liao, R. N. S. Sodhi, and T. W. Coyle, J. Vac. Sci. Technol. A 11, 2681 (1993).

${ }^{28}$ C. K. Hwangbo, L. J. Lingg, J. P. Lehan, H. A. Macleod, and F. Suits, Appl. Opt. 28, 2779 (1989).

${ }^{29}$ A. D. Katnani and K. I. Papathomas, J. Vac. Sci. Technol. A 5, 1335 (1987).

${ }^{30}$ A. Jablonski and C. J. Powell, J. Vac. Sci. Technol. A 21, 274 (2003).

${ }^{31}$ S. Spruytte, C. Coldren, J. Harris, D. Pantelidis, H.-J. Lee, J. Bravman, and M. Kelly, J. Vac. Sci. Technol. A 19, 603 (2001).

${ }^{32}$ C. J. Powell, J. Vac. Sci. Technol. A 3, 1338 (1985).

${ }^{33}$ NIST Standard Reference Database 82, NIST Electron EffectiveAttenuation-Length Database, National Institute of Standards and Technology, Gaithersburg, MD.

${ }^{34}$ M. Le Gall, B. Lesage, and J. Bernardini, Philos. Mag. A 73, 899 (1996).

${ }^{35}$ D. Westwood, R. A. Youngman, M. R. McCartney, A. N. Cormack, and M. R. Notis, J. Mater. Res. 10, 1271 (1995).

${ }^{36}$ H. Schmalzried, Solid State Reactions (Academic, New York, 1974).

${ }^{37}$ J. H. Edgar, Properties of Group III Nitrides (Electronic Materials Information Service, London, 1994).

${ }^{38}$ P. M. Dryburgh, J. Cryst. Growth 94, 23 (1989).

${ }^{39}$ V. S. Ban, J. Electrochem. Soc. 119, 761 (1972).

${ }^{40}$ J. Hille, Chem. Tech. (Leipzig) 18, 466 (1966).

${ }^{41}$ A. A. Tsyganenko, D. V. Pozdnyakov, and V. N. Filimonov, J. Mol. Struct. 29, 299 (1975).

${ }^{42}$ R. Shekhar and K. F. Jensen, Surf. Sci. 381, L581 (1997).

${ }^{43}$ S. Kagami, T. Onishi, and K. Tamaru, J. Chem. Soc., Faraday Trans. 180 , 29 (1984).

${ }^{44}$ A. C. Dillon, P. Gupta, M. B. Robinson, A. S. Bracker, and S. M. George, 
J. Vac. Sci. Technol. A 9, 2222 (1991).

${ }^{45}$ H. Schmalzried, Chemical Kinetics of Solids (VCH, New York, 1995), p. 137.

${ }^{46}$ A. Serrari, J. L. Chartier, and R. Le Bihan, Appl. Surf. Sci. 51, 133 (1991).
${ }^{47}$ J. H. Scofield, J. Electron Spectrosc. Relat. Phenom. 8, 129 (1976).

${ }^{48}$ H. Solmon, D. Robinson, and R. Dieckmann, J. Am. Ceram. Soc. 77, 2841 (1994).

${ }^{49}$ M. Sternitzke and G. Muller, J. Am. Ceram. Soc. 77, 737 (1994). 